\title{
Revisión
}

\section{Los derechos exclusivos de propiedad intelectual en la jurisprudencia hondureña}

\author{
Exclusive intellectual property rights in Honduran jurisprudence \\ Efigenia Alejandra Leiva Guerra, ${ }^{1}$ Ivanna Elizabeth Campbell Caballero \\ Facultad de Postgrado, Universidad Tecnológica Centroamericana, San Pedro Sula, Honduras
}

\author{
Historia del artículo: \\ Recibido: 9 agosto 2019 \\ Revisado: 12 agosto 2019 \\ Aceptado: 13 noviembre 2019 \\ Publicado: 30 diciembre 2019 \\ Palabras clave \\ Derechos exclusivos \\ Derecho libre de competencia \\ Marcas \\ Propiedad intelectual \\ Patentes \\ Keywords \\ Antitrust Law \\ Brands \\ Exclusive rights \\ Intellectual property \\ Patents
}

\begin{abstract}
RESUMEN. Introducción: La protección de los derechos de propiedad intelectual usando los mecanismos legales actuales, tiene como su principal objetivo incentivar la inventiva y la innovación, facilitando la explotación comercial. Por otra parte, la libre competencia tiene la misión de promover, proteger y garantizar la libertad para competir a fin de procurar el funcionamiento eficiente del mercado y el bienestar del consumidor. Métodos: Se hizo revisión bibliográfica en bases de revistas y en colección de leyes hondureñas y extranjeras referentes a la propiedad intelectual y el derecho de libre competencia con respecto a los derechos exclusivos. Desarrollo: Se muestran características, diferencias, puntos de divergencia y convergencias entre ambos estamentos legales de Honduras, en donde se considera la importancia de lograr un equilibrio de los fines comunes que persiguen estas figuras jurídicas. Conclusión: Debe socializarse y seguir una mejora continua de dicha legislación para procurar el bienestar colectivo (país, empresas, consumidores) introduciendo mayor competitividad al mercado, impulso de la innovación e invención, economía más eficiente, y sobre todo velar por el bienestar del consumidor, derecho que el Estado debe garantizar.

ABSTRACT. Introduction: Protection of intellectual property rights using current legal mechanisms has as its main objective to encourage invention and innovation, facilitating commercial exploitation. On the other hand, free competition has the mission of promoting, protecting and guaranteeing the freedom to compete in order to ensure the efficient functioning of the market and consumer welfare. Methods: The authors completed a bibliographic review using journal databases and collections of Honduran and foreign laws regarding intellectual property and the right to free competition with respect to exclusive rights. Results: We show characteristics, differences, points of divergence and convergence between the two Honduran legal bodies and consider the importance of achieving a balance of the common goals pursued by these legal figures. Conclusion: There exists a need to make legislation known to the public and follow up with continuous improvement of such legislations to promote the collective well-being of the country, companies, and consumer; this resulting, ideally in the introduction of greater competitiveness to the market, promotion of innovation, a more efficient economy and above all to ensure consumer welfare; a right that the State must guarantee.
\end{abstract}

\section{Introducción}

A través de su historia, la humanidad ha tenido épocas de progreso cultural o tecnológico variable: épocas como la edad media, en que la sociedad evolucionó limitadamente en sus conocimientos y otras épocas de grandes cambios, como ocurrió durante el renacimiento o revolución industrial, que han generado una auténtica revolución cultural y tecnológica. La propiedad intelectual ha ido de la mano con la evolución de la sociedad, guardando una estrecha relación con las creaciones del intelecto humano, siendo clave promover su protección, desarrollo e innovación. En tiempos en que los bienes intangibles (información, conocimientos, procedimientos) son la fuente de riqueza predominante en las economías modernas, la propiedad intelectual surge con el objeto de proteger esos bienes intangibles como ser los derechos de autor, derechos conexos y derechos de propiedad industrial.

El derecho de propiedad intelectual esta sostenido en el derecho real de propiedad, cuya protección puede otorgarse por medio de derechos exclusivos. Los derechos exclusivos son privilegios de uso y explotación que otorga el Estado a los autores e inventores. Ambas figuras legales importan al

\footnotetext{
${ }^{1}$ Autor corresponsal: efileiva@ hotmail.com, Facultad de Posgrado, UNITEC, Km. 5 carretera a Puerto Cortés, San Pedro Sula, Honduras.

Disponible en https://doi.org/10.5377/innovare.v8i2.9041

Este es un artículo de acceso abierto bajo la licencia http://creativecommons.org/licenses/by-nc-nd/4.0
} 
impulsar el crecimiento y la eficiencia económica a través de los mercados. Si vinculamos lo anterior al derecho de libre competencia, éste constituye un incentivo para el desarrollo de nuevas obras e invenciones con el objetivo de satisfacer las necesidades demandadas por la sociedad.

Para lograr la innovación, la competencia de los mercados y el crecimiento económico es importante plantearse las siguientes preguntas: ¿Cómo conciliar los privilegios particulares y temporales (derechos exclusivos) que se conceden a los diferentes titulares de derechos de propiedad intelectual, con el derecho de libre competencia del mercado de bienes intelectuales? Parra Satizábal (2002) afirma que existe un vínculo muy cercano entre las figuras jurídicas de propiedad intelectual y el derecho de libre competencia, que interactúan con los diferentes principios y fundamentos de derecho de la competencia.

La política de defensa de la competencia tiene por objeto promover y proteger el ejercicio de la libre competencia, garantizando el funcionamiento del libre mercado, donde la oferta y demanda, sean los parámetros de comercialización; es por ello que cuando se habla de derechos exclusivos son catalogados desde dos perspectivas: (a) como restricción a la libre competencia y (b) como instrumento para impulsarla a la libre competencia.

Con el primer punto de vista, Parra Satizábal (2002) comenta que el hecho de obtener un derecho exclusivo para explotar un producto o procedimiento (patente) implica per se la posibilidad de evitar que terceros puedan explotar esa invención. Por lo tanto, la consecuente monopolización de un elemento competitivo en el mercado. Con respecto al segundo punto de vista, la apertura de las economías, la globalización de las actividades productivas y comerciales y la liberación de los mercados han constituido factores determinantes para el realce y la renovación del papel que juegan las disciplinas jurídicas de propiedad intelectual y la libre competencia.

La relación entre ambas disciplinas legales parece contradictoria, ya que una promueve la libre competencia y la otra promueve los privilegios temporales (derechos exclusivos) en los bienes intelectuales. Sin embargo, se expone que ambas disciplinas pueden resultar conciliables y complementarias, especialmente cuando se considera a la propiedad intelectual como factor clave para el desarrollo y crecimiento de la economía del país, el cual es logrado mediante posiciones claras y equilibradas, así como las buenas prácticas de cumplimiento de los titúlales e instituciones involucradas.

\section{Métodos}

Se hizo revisión bibliográfica en bases de revistas y en colección de leyes hondureñas y extranjeras referentes a la propiedad intelectual y el derecho de libre competencia con respecto a los derechos exclusivos. Se procuró la descripción de la evolución que ha tenido la propiedad intelectual en el mundo y especialmente en Honduras. El Cuadro 1 muestra las variables y definiciones que se usaron para la revisión.

\section{Cuadro 1}

Variables y definiciones usadas sobre la propiedad intelectual y la libre competencia.

\begin{tabular}{|c|c|c|}
\hline Variables & Definición & Operatividad \\
\hline $\begin{array}{l}\text { Derechos } \\
\text { exclusivos en } \\
\text { materia de } \\
\text { propiedad } \\
\text { intelectual }\end{array}$ & $\begin{array}{l}\text { El reconocimiento o } \\
\text { la concesión de } \\
\text { derechos de } \\
\text { propiedad intelectual } \\
\text { a personas para } \\
\text { producir un bien y } \\
\text { restringir el uso del } \\
\text { mismo por parte de } \\
\text { terceros (OMPI, } \\
\text { 2018) }\end{array}$ & $\begin{array}{l}\text { Normativa legal, } \\
\text { jurisprudencias } \\
\text { administrativa y } \\
\text { judicial, así como } \\
\text { doctrina en materia } \\
\text { de propiedad } \\
\text { intelectual con } \\
\text { énfasis en derechos } \\
\text { exclusivos (Ortiz, } \\
\text { 2011) }\end{array}$ \\
\hline $\begin{array}{l}\text { Libre } \\
\text { competencia }\end{array}$ & $\begin{array}{l}\text { Situación en la cual } \\
\text { existen las } \\
\text { condiciones para que } \\
\text { un agente económico, } \\
\text { sea oferente o } \\
\text { demandante, tenga } \\
\text { completa libertad de } \\
\text { participar en el } \\
\text { mercado (Congreso } \\
\text { Nacional de } \\
\text { Honduras, 2006) } \\
\end{array}$ & $\begin{array}{l}\text { Normativa legal, } \\
\text { jurisprudencias } \\
\text { administrativa y } \\
\text { judicial, doctrina en } \\
\text { materia de libre } \\
\text { competencia con } \\
\text { énfasis en derechos } \\
\text { exclusivos (Noboa } \\
\text { Pagán, 2019) }\end{array}$ \\
\hline $\begin{array}{l}\text { Bienes } \\
\text { intelectuales } \\
\text { en sus varias } \\
\text { formas }\end{array}$ & $\begin{array}{l}\text { Consiste en todas las } \\
\text { obras y creaciones de } \\
\text { bienes o servicios } \\
\text { creados a partir de la } \\
\text { inventiva del ser } \\
\text { humano, con el } \\
\text { objetivo de suplir una } \\
\text { necesidad (CIM, } \\
\text { 2019) }\end{array}$ & $\begin{array}{l}\text { Normativa legal, } \\
\text { doctrina en materia } \\
\text { de propiedad } \\
\text { intelectual (OMPI, } \\
\text { 2018) }\end{array}$ \\
\hline
\end{tabular}

\section{Desarrollo}

\subsection{Macroentorno}

La creciente importancia en la innovación y en el desarrollo tecnológico de los bienes y servicios ha obligado a los Estados a reconsiderar las legislaciones adoptadas en la propiedad intelectual y derecho a la libre competencia. $\mathrm{La}$ globalización de los mercados y la creciente interrelación económica entre naciones ha situado las soluciones adoptadas en la propiedad intelectual y derecho a la libre competencia en un plano internacional (Ginebra Serrabou, 2007). 
La Organización Mundial de la Propiedad Intelectual (OMPI) tiene el propósito del desarrollo de un sistema internacional de propiedad intelectual que sea equilibrado y eficaz, permitiendo la innovación y la creatividad, con el fomento del uso y la protección de los bienes intelectuales. La OMPI (2018) ofrece tres razones diferentes para la protección y promoción de los derechos de propiedad intelectual. Primeramente, la OMPI describe que el progreso y el bienestar de la humanidad dependen de su capacidad de crear e inventar nuevas obras en las esferas de la tecnología y la cultura. En segundo lugar, la OMPI detalla que la protección jurídica de las nuevas creaciones alienta a destinar recursos adicionales a la innovación. En tercer lugar, la OMPI menciona que la promoción y la protección de la propiedad intelectual estimulan el crecimiento económico, generan nuevos empleos e industrias y enriquecen y mejoran la calidad de vida (OMPI, 2018).

Cuadro 2

Teorías de sustento a la propiedad intelectual y a los derechos exclusivos a nivel nacional e internacional.

\begin{tabular}{ll}
\hline Sistema jurídico & Descripción \\
\hline Constitución de la República de & - Decreto Número N ${ }^{\circ} 131$ \\
Honduras & \\
\hline Leyes Nacionales & - Ley del Derecho de Autor y de los Derechos Conexos (SICE, 2019) \\
& - Ley de Propiedad Industrial (Poder Judicial de Honduras, 2000) \\
& - Ley para la Defensa y Promoción de la Competencia (Congreso Nacional de Honduras, \\
& $2006)$ \\
\hline Tratados Internacionales & - Convenio de Berna para la Protección de las Obras Literarias y Artísticas (OMPI, s.f.) \\
& - Convenio de París para la Protección de la Propiedad Industrial (OMPI, 1979) \\
& - Acuerdos sobre los Aspectos de los Derechos de Propiedad Intelectual relacionados \\
& con el Comercio (ADPIC) (WTO, s.f.) \\
& - Tratado de Libre Comercio entre Estados Unidos, Centroamérica y República \\
& Dominicana (DR-CAFTA) (OMPI, 2006) \\
\hline Jurisprudencia & Judicial \\
& - Administrativa \\
\hline Doctrina & - Teoría sobre el incentivo al inventor (Encaoua, Guellec \& Martínez, 2011) \\
& - La importancia del derecho exclusivo en la economía (Sanromán, 2014). \\
& - La libre competencia y su impacto en la economía \\
\hline
\end{tabular}

\subsection{Microentorno}

El Gobierno de Honduras acordó la creación de la Oficina de Patentes y Marcas el 7 de marzo de 1902. Esta iniciativa surgió ante la necesidad de proteger los activos intangibles de los emprendedores y empresarios. Después de varios cambios y con la última reforma aprobada, se determinó que la oficina encargada de la propiedad industrial fuera la Dirección General de Propiedad Intelectual (DIGEPIH), como una dependencia del Instituto de la Propiedad (Instituto de la Propiedad de Honduras, 2017). Honduras se adhirió a la OMPI el 3 de noviembre de 1993.

La adhesión del país se hizo para promover la protección de la propiedad intelectual para permitir la innovación y la creatividad, así como el respeto a los acuerdos, convenios y tratados internacionales suscritos en esta materia por Honduras (Instituto de la Propiedad de Honduras, 2017; Discua Singh, 2018; Escobar, 2018). La Constitución de la República de Honduras mediante la Asamblea Nacional Constituyente (1982), dice: "Todo autor, inventor, productor o comerciante gozará de la propiedad exclusiva de su obra, invención, marca o nombre comercial con arreglo a la ley."
Según los derechos exclusivos se puede cuestionar sobre el trato especial que recibe la propiedad intelectual, ya que la Asamblea Nacional Constituyente (1982) estableció en la Constitución de la República de Honduras en su Artículo 339 que "Se prohíben los monopolios, monopsonios, oligopolios, acaparamiento y prácticas similares en la actividad industrial y mercantil. No se consideran monopolios particulares los privilegios temporales que se concedan a los inventores, descubridores o autores en concepto de derechos de propiedad científica, literaria, artística o comercial, patentes de invención y marcas de fábricas."

\subsection{Teorías de sustento}

Aportan los puntos de vista con respecto al problema planteado sobre la relación existente entre propiedad intelectual y derecho de libre competencia, enfocado en el tema de derechos exclusivos. Entre las teorías de sustento destacadas tenemos: la carta magna del país, la Constitución de la República de Honduras, tratados internacionales, normativa legal nacional, jurisprudencia, doctrina legal, así 
como, información recolectada en entrevistas con informantes claves y expertos (Cuadro 2). Sin embargo, de esta estadística, en Honduras se encuentran 5,067 patentes registradas, de esa cantidad, muchas pueden estar vencidas, formando parte del dominio público, ya que su titular no cuenta con el privilegio de explotación exclusiva. Según los datos ofrecidos por el Instituto de la Propiedad, entre los años 2014 - 2017, se presentaron 366 registros de patentes, 917 registros de derechos de autor y conexos y 23,466 registro de marcas.

Con respecto a la Denominación de Origen, su registro tiene importancia dada la reputación de este signo distintivo, el cual se ha convertido en un bien colectivo intangible, con un alto valor comercial, por ende, debe ser protegida contra el uso ilegítimo por parte de terceros, que desarrollan su actividad en zonas distintas a la delimitada o contra aquellos productores que, a pesar de pertenecer a dicha área, no se apegan a las prácticas y métodos de producción y calidad exigidos.

En Honduras existe solo una denominación de origen registrada y consiste en la Denominación de Origen Café Marcala, la cual fue reconocida en fecha 18 de noviembre del 2005 y cuyo objetivo principal para ese entonces, era evitar la usurpación del nombre de Márcala en la comercialización del café.

\subsection{Convergencia de los derechos exclusivos de propiedad intelectual y el derecho de libre competencia}

La Figura 1 resume la interacción entre el derecho de propiedad intelectual y derecho de libre competencia identificando cinco elementos de convergencia entre ambas ramas legales. Es necesario analizar en qué puntos estas ramas del derecho y a figura legal del "derecho exclusivo", pueden alcanzar un equilibrio y converger entre sí para potenciar la economía del país y producir un bienestar colectivo (país, empresas y consumidores). Ver también el Cuadro 3.

\subsection{Promover las innovaciones}

Los mercados que se encuentran en libre competencia, incentivan y motivan a los agentes económicos a innovar en sus productos, servicios y procesos para hacerlos más rentables y estar a la vanguardia comercial satisfaciendo las necesidades de los consumidores. El éxito comercial de una innovación depende de varios actores haciendo uso eficaz de las herramientas de propiedad intelectual y de esta manera lograr un equilibrio entre ambas ramas del derecho, las cuales conjuntamente logran promover un ambiente adecuado de innovación (Kalanje, 2018).

Cuadro 3

Siete características del derecho de propiedad intelectual y del derecho de libre competencia según la literatura.

\begin{tabular}{|c|c|c|c|}
\hline \multicolumn{2}{|c|}{ Temas } & \multirow{2}{*}{$\begin{array}{l}\text { Derecho de propiedad intelectual } \\
\text { Incentivar la inversión en innovaciones y creaciones, } \\
\text { así como su aplicación }\end{array}$} & \multirow{2}{*}{$\begin{array}{l}\text { Derecho de libre competencia } \\
\text { La ordenación de los mercados, para } \\
\text { beneficio de los consumidores }\end{array}$} \\
\hline 1. & Objetivo & & \\
\hline 2. & $\begin{array}{l}\text { Protección/ } \\
\text { Defensión }\end{array}$ & $\begin{array}{l}\text { Protege los bienes intelectuales mediante los derechos } \\
\text { exclusivos }\end{array}$ & $\begin{array}{l}\text { Defiende la libre competencia de conductas } \\
\text { restrictivas ilegales mediante la eliminación } \\
\text { de barreras }\end{array}$ \\
\hline 3. & Beneficiarios & $\begin{array}{l}\text { Creadores, innovadores, inventores. En general, las } \\
\text { personas que se convertirán en proveedores }\end{array}$ & Los consumidores \\
\hline 4. & $\begin{array}{l}\text { Aspectos } \\
\text { territoriales }\end{array}$ & $\begin{array}{l}\text { La política en materia de propiedad intelectual está } \\
\text { determinada por el derecho internacional, en particular } \\
\text { en el caso de los países en desarrollo }\end{array}$ & $\begin{array}{l}\text { Legislación nacional en materia de } \\
\text { competencia }\end{array}$ \\
\hline 5. & Ente Regulador & $\begin{array}{l}\text { Dirección General de Propiedad Intelectual de } \\
\text { Honduras (DIGEPIH) }\end{array}$ & $\begin{array}{l}\text { Comisión para la Defensa y Promoción de } \\
\text { la Competencia (CDPC) }\end{array}$ \\
\hline 6. & $\begin{array}{l}\text { Fundamentación } \\
\text { legal }\end{array}$ & $\begin{array}{l}\text { Constitución de la República, Artículos 108, } 339 \\
\text { (Poder Judicial de Honduras, 1982) }\end{array}$ & $\begin{array}{l}\text { Constitución de la República, Artículo } 339 \\
\text { (Poder Judicial de Honduras, 1982) }\end{array}$ \\
\hline 7. & $\begin{array}{l}\text { Legislación } \\
\text { Nacional }\end{array}$ & $\begin{array}{l}\text { Ley de Propiedad Industrial (Poder Judicial de } \\
\text { Honduras, 2000) } \\
\text { Ley de Derechos de Autor y Derechos Conexos } \\
\text { (OMPI, 1999) }\end{array}$ & $\begin{array}{l}\text { Ley para la Defensa y Promoción de la } \\
\text { Competencia (Congreso Nacional de } \\
\text { Honduras, 2006) }\end{array}$ \\
\hline
\end{tabular}




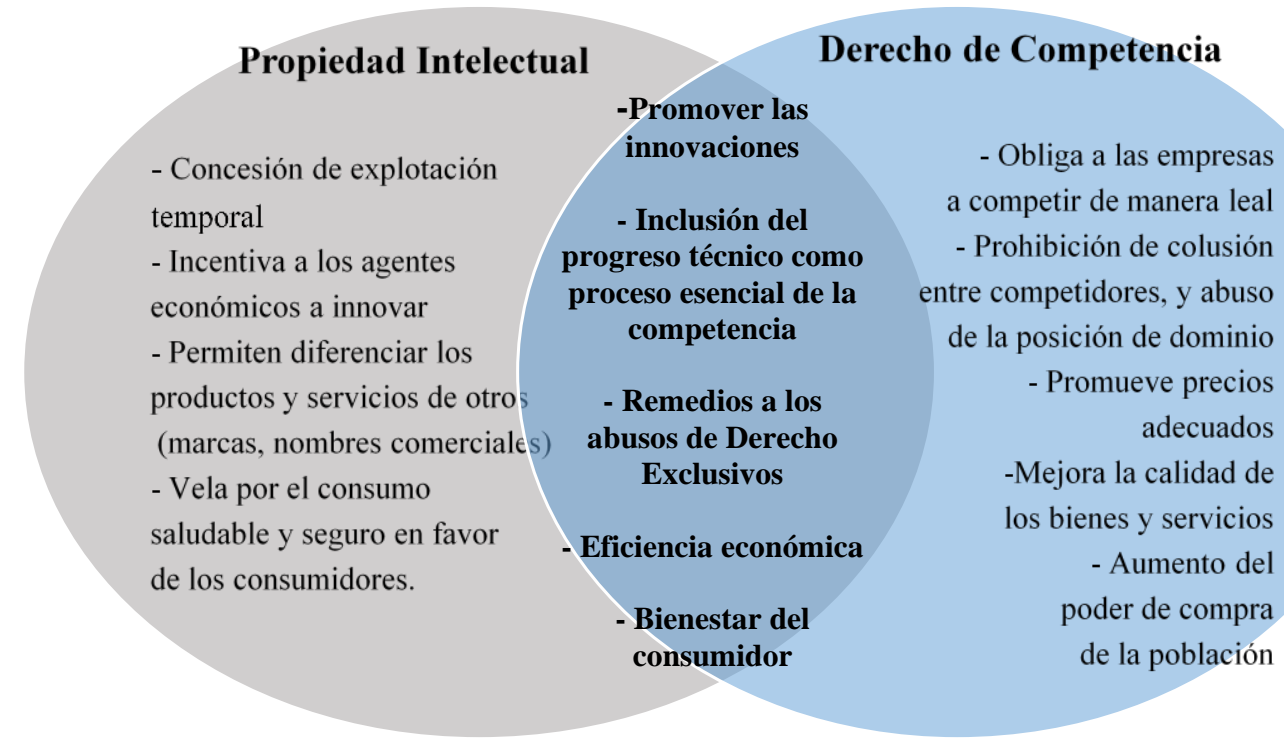

Figura 1 Puntos de divergencia y convergencia de los derechos exclusivos.

\section{Cuadro 4}

Figuras jurídicas al amparo de la propiedad intelectual.

\begin{tabular}{|c|c|}
\hline Figura Jurídica & Tiempo de explotación \\
\hline $\begin{array}{l}\text { 1. Derechos de Autor (Obras Literarias, Obras } \\
\text { Artísticas) }\end{array}$ & Están protegidos durante la vida del autor y 75 años después de su muerte \\
\hline $\begin{array}{l}\text { 2. Derechos Conexos (Artistas Intérpretes o } \\
\text { Ejecutantes, Reproductores de fonogramas, } \\
\text { Organismos de radiodifusión) }\end{array}$ & $\begin{array}{l}\text { Será de } 75 \text { años contados a partir: } \\
\text { - Del final del año de la fijación, para los fonogramas y a las } \\
\text { interpretaciones o ejecuciones grabadas en ellos. } \\
\text { - Del final del año en que se haya realizado la actuación, para las } \\
\text { interpretaciones o ejecuciones que no estén grabadas en un fonograma. } \\
\text { - Del final del año en que se haya realizado la emisión, para las emisiones } \\
\text { de radiodifusión }\end{array}$ \\
\hline 3. Patentes de Invención & $\begin{array}{l}20 \text { años improrrogables, contados a partir de la fecha de presentación de la } \\
\text { solicitud de registro ante autoridad competente }\end{array}$ \\
\hline 4. Patente: Modelos de Utilidad & $\begin{array}{l}15 \text { años contados a partir de la fecha de presentación de la solicitud de } \\
\text { registro ante autoridad competente }\end{array}$ \\
\hline 5. Patente: Diseños Industriales & $\begin{array}{l}5 \text { años contados a partir de la fecha de presentación de la solicitud de } \\
\text { registro ante autoridad competente, prorrogables, por dos períodos } \\
\text { adicionales }\end{array}$ \\
\hline 6. Signo Distintivo: Marcas (de fábrica, de servicio) & 10 años, desde la fecha de concesión del registro. Puede renovarse \\
\hline 7. Signo Distintivo: Nombre Comercial & Vigencia de la empresa mercantil que lo utiliza \\
\hline $\begin{array}{l}\text { 8. Signo Distintivo: Expresiones o señales de } \\
\text { propaganda }\end{array}$ & 10 años renovables, a partir de su inscripción \\
\hline 9. Signo Distintivo: Emblema & Vigencia de la empresa mercantil que lo utiliza \\
\hline 10. Signo Distintivo: Indicación Geográfica & Indefinido \\
\hline 11. Signo Distintivo: Denominación de Origen & Indefinido \\
\hline
\end{tabular}




\section{Cuadro 5}

Histórico registral de propiedad intelectual a septiembre 2018 por tipo de registro.

\begin{tabular}{|c|c|c|c|c|}
\hline \multicolumn{5}{|l|}{ Registros de marcas } \\
\hline \multirow{2}{*}{\multicolumn{2}{|c|}{$\begin{array}{l}\text { PI-Signos } \\
\text { Distintivos/Marcas }\end{array}$}} & Nacionales & Internacionales (No & Total Parcial \\
\hline & & (Residente) & Residentes) & \\
\hline \multicolumn{2}{|c|}{ Denominaciones de Origen } & 1 & 88 & 89 \\
\hline \multicolumn{2}{|c|}{ Marcas Sonoras } & 1 & 0 & 1 \\
\hline \multicolumn{2}{|l|}{ Emblemas } & 369 & 71 & 440 \\
\hline \multicolumn{2}{|l|}{ Indicaciones Geográficas } & 10 & 32 & 42 \\
\hline \multicolumn{2}{|l|}{ Marcas Colectivas } & 28 & 11 & 39 \\
\hline \multicolumn{2}{|l|}{ Marcas de Certificación } & 38 & 7 & 45 \\
\hline \multicolumn{2}{|l|}{ Marcas de Fábrica } & 19,991 & 100,906 & 120,897 \\
\hline \multicolumn{2}{|l|}{ Marcas de Servicios } & 7,170 & 18,487 & 25,657 \\
\hline \multicolumn{2}{|l|}{ Nombres Comerciales } & 4,684 & 1,334 & 6,018 \\
\hline \multicolumn{2}{|l|}{ Señales de Propaganda } & 1,608 & 3,467 & 5,075 \\
\hline \multicolumn{2}{|l|}{ Total } & 33,900 & 124,403 & 158,303 \\
\hline \multicolumn{5}{|l|}{ Registros de patentes } \\
\hline \multirow[t]{2}{*}{ PI-Patentes } & Nacionales (Residentes) & \multicolumn{2}{|c|}{ Internacionales (No Residentes) } & Total Parcial \\
\hline & & $\begin{array}{l}\text { Tradicional } \\
\text { (Convenio París) }\end{array}$ & $\begin{array}{l}\text { Sistema Internacional } \\
\text { Patentes (PCT) }\end{array}$ & \\
\hline Invención (PI) & 757 & 1,718 & 2,592 & 5,067 \\
\hline $\begin{array}{l}\text { Modelo de Utilidad } \\
\text { (MU) }\end{array}$ & 30 & 168 & 0 & 198 \\
\hline Diseño Industrial (DI) & 103 & 582 & 0 & 685 \\
\hline Total & 890 & 2,468 & 2,592 & 5,950 \\
\hline \multicolumn{5}{|c|}{ Registros de derechos de autor y derechos conexos } \\
\hline \multicolumn{2}{|c|}{ Derechos de autor y de los Derechos Conexos } & Nacionales & Internacionales & Total Parcial \\
\hline \multicolumn{2}{|c|}{ Obras Literarias } & 3,082 & 0 & 3,082 \\
\hline \multicolumn{2}{|c|}{ Obras Musicales/Artísticas } & 1,470 & 0 & 1470 \\
\hline \multicolumn{2}{|c|}{ Obras Fonogramas } & 135 & 0 & 135 \\
\hline \multicolumn{2}{|l|}{ Obras de Software } & 215 & 0 & 215 \\
\hline \multicolumn{2}{|c|}{ Obras Cinematográficas/Audiovisuales } & 139 & 0 & 139 \\
\hline \multicolumn{2}{|c|}{ Contratos } & 733 & 0 & 733 \\
\hline \multicolumn{2}{|l|}{ Total } & 5,774 & $\mathbf{0}$ & 5,774 \\
\hline
\end{tabular}

\subsection{Promover las innovaciones}

Los mercados que se encuentran en libre competencia, incentivan y motivan a los agentes económicos a innovar en sus productos, servicios y procesos para hacerlos más rentables y estar a la vanguardia comercial satisfaciendo las necesidades de los consumidores. El éxito comercial de una innovación depende de varios actores haciendo uso eficaz de las herramientas de propiedad intelectual y de esta manera lograr un equilibrio entre ambas ramas del derecho, las cuales conjuntamente logran promover un ambiente adecuado de innovación (Kalanje, 2018).

\subsection{Inclusión del progreso técnico como proceso esencial de la competencia}

Las empresas analizan sus procesos de producción y hacen una evaluación de sus productos y servicios, realizan las mejoras y otorgan beneficios a los consumidores con respecto a la calidad, precios y variedad. Esta es una manera más para continuar compitiendo en los diferentes mercados (Espinoza, 2018).

\subsection{Remedios a los abusos de Derechos Exclusivos}

El Artículo 8.2 de los Aspectos de los Derechos de Propiedad Intelectual relacionados con el Comercio (ADPIC) menciona sobre "aplicar medidas necesarias" para prevenir el abuso de los derechos de propiedad intelectual. El Artículo 30 del acuerdo sobre los ADPIC, trata la cuestión de las excepciones sólo en términos generales, deja a los Estados Miembros de la Organización Mundial del Comercio (OMC) un margen considerable de libertad con respecto a la definición de la naturaleza y amplitud de las excepciones a los derechos exclusivos de los titulares de patentes. Los remedios más destacados en nuestro país son:

- Licencias Obligatorias, en el caso de abuso de patentes

- Excepción Bolar o Explotación Temprana

- Hacer que las excepciones que existan se potencien dentro del sistema 


\subsection{Eficiencia económica}

Una de las características que obtiene como resultado de un equilibrio en el tema de derechos exclusivos en materia de propiedad intelectual y de libre competencia. Se puede determinar el beneficio en la economía del país, desarrollando una forma más equitativa del comercio donde se promueve la innovación, la inventiva en los bienes y servicios que se ofrecen a los consumidores. El resultado es la creación de nuevas empresas y nuevas oportunidades de empleo. Las innovaciones en los procesos y procedimientos, los hace más expeditos y eficientes, generando mayor productividad convertida en beneficios a los consumidores.

\subsection{Bienestar del consumidor}

Características más sobresaliente e importante, resultado de la convergencia existente entre la propiedad intelectual y la libre competencia, la cual demuestra que cuando existe un equilibrio, el resultado más evidente es el bienestar del consumidor. Podemos destacar los siguientes aspectos:

a. Las empresas se esfuerzan por ser mejores que sus competidores, reduciendo precios, aumentando la calidad de sus productos o servicios y atrayendo más consumidores

b. Se potencia la libertad de elegir de los consumidores al escoger entre marcas

c. Se promueve e impulsa la innovación y el progreso técnico de las empresas

d. Se protege la seguridad y se le da tranquilidad al consumidor, invirtiendo en bienes y servicios auténticos.

e. Hay transparencia entre los competidores, originando un mercado sano, competitivo y justo.

\section{Conclusión}

La Constitución de la República de Honduras, con su Artículo 339 menciona que prohíbe los monopolios en la actividad industrial y mercantil, sin embargo, excluye la propiedad intelectual de esta prohibición, esto debido a que el legislador no lo considero de esa forma, fundamentándose en que proteger la propiedad intelectual por medio de "derechos exclusivos" de explotación es con el fin de potenciar la creatividad y la innovación entre la población; ya que si el legislador la hubiese calificado como un monopolio per se, se hubiera estado condenando a que no existieran incentivos para inventar, innovar, invertir en investigación y desarrollo de nuevos productos y tecnologías. Es importante tener claridad que referirse a monopolio, su enfoque es a una sola empresa y derechos exclusivos es el derecho que se deriva a partir de una creación, invención e innovación.
La aceleración de la innovación en una economía globalizada hace que el comercio internacional este en constante crecimiento, planteando nuevos temas y retos, tal es el caso de la interacción de propiedad intelectual y las leyes de competencia, a primera vista pareciera que persiguen objetivos opuestos, la primera otorga monopolios/concesiones temporales, mientras que la segunda protege al mercado de los comportamientos monopolísticos, sin embargo, comparten fundamentos en común, haciéndolas converger en ciertos puntos y fines comunes, como ser la introducción de mayor competitividad al mercado, impulsar la innovación e invención, eficientar la economía y velar por el bienestar del consumidor.

La resolución de tensiones que se suscitan con el tema de derechos exclusivos en materia de propiedad intelectual y del derecho de libre competencia, disponen de una variedad de mecanismos que pueden ser utilizados por los titulares de derechos intelectuales, (1) procedimientos administrativos que incluyen multas administrativas, (2) procedimientos judiciales mediante la acción civil o la acción penal, dependiendo la infracción y el daño cometido; y (3) procedimiento arbitral donde las partes en controversia de común acuerdo deciden solventar su problema, con rapidez y confidencialidad del proceso. Sin embargo, todo este procedimiento se puede evitar mediante posiciones claras y equilibradas, así como las buenas prácticas de cumplimiento de los titúlales e instituciones involucradas.

\section{Contribuciones de los Autores}

Las autoras participaron en la revisón de la literatura y redactaron el artículo de revisión.

\section{Conflictos de Interés}

Las autoras declaran no tener ningún conflicto de interés.

\section{Referencias Bibliográficas}

Asamblea Nacional Constituyente. Código Civil, Pub. L. No. Decreto 76 (1906), Cap. II Cosas Incorporales Título II - Del Dominio, Decreto 76 136 (1906).

Asamblea Nacional Constituyente. Constitución de la República de Honduras (1982), Decreto $\mathrm{N}^{\circ} 131$ Constitución de la República de Honduras.

Centro de Investigación de Mercados [CIM]. (2019). ¿Porque para las empresas es indispensable satisfacer necesidades? Disponible en: http://www.ciminvestigacion.com/por-que-para-las-empresas-esindispensable-satisfacer-necesidades/.

Congreso Nacional de Honduras. (2006). Ley para la Defensa y Promoción de la Competencia, Pub. L. No. 30, 920, 357-2005.

Discua Singh, M. (2018). Los derechos exclusivos de propiedad intelectual en la jurisprudencia hondureña. [Comunicación personal]. 
Encaoua, D., Guellec, D., \& Martínez, C. (2011). Sistemas de patentes para fomentar la innovacion: lecciones de analisis economico. Juan Aboites y Juan Manuel Corona. Economía de la innovacion y desarollo, siglo veintiuno, siglo XXI editores, México, Universidad Autonoma Metropolitana, Unidad Xochimilco, p..398-430

Escobar, R. H. (2018). Los derechos exclusivos de propiedad intelectual en la jurisprudencia hondureña. [Comunicación personal].

Espinoza, E. (2018). La innovación y las empresas en Centroamérica: hacia una nueva era. Disponible en: http://dataexport.com.gt/la-innovaciony-las-empresas-en-centroamerica-hacia-una-nueva-era/.

Ginebra Serrabou, X. (2007). La propiedad intelectual y la competencia económica en México. Bol. Mex. Der. Comp., vol. 41, no. 121.

Instituto de la Propiedad de Honduras. (2017). Honduras conmemora 115 años de historia de la propiedad intelectual. Disponible en: http://www.ip.gob.hn/content/honduras-conmemora-115a\%C3\%B1 os-de-historia-de-la-propiedad-intelectual.

Kalanje, C.M. (2018). El papel de la propiedad intelectual en la innovación y el desarrollo de nuevos productos [Página Web Oficial]. Disponible en:

http://www.wipo.int/sme/es/documents/ip_innovation_development.ht $\mathrm{m}$.

Noboa Pagán, A. (2019). Principio constitucional de eficiencia de la función administrativa y la política persecutoria para la defensa a la competencia en la República Dominicana. Asociación Latinoamericana e Ibérica de Derecho y Economía (ALACDE). $23^{\circ}$ Conferencia Anual. Universidad Panamericana de México.

Organización Mundial de la Propiedad Intelectual [OMPI]. (2018). ¿Qué es la propiedad intelectual? Disponible en: http://www.wipo.int/aboutip/es/.

Organización Mundial de la Propiedad Intelectual [OMPI]. (2018). Arbitraje [Institucional]. Disponible en: http://www.wipo.int/amc/es/arbitration/procedures/.

Organización Mundial de la Propiedad Intelectual [OMPI]. (s.f.). Reseña del Convenio de Berna para la Protección de las Obras Literarias y Artísticas (1886). Disponible en: https://www.wipo.int/treaties/es/ip/berne/summary_berne.html.

Organización Mundial de la Propiedad Intelectual [OMPI]. (1979). Convenio de París para la Protección de la Propiedad Industrial.
Disponible

https://www.wipo.int/treaties/es/text.jsp?file_id=288515.

Organización Mundial de la Propiedad Intelectual [OMPI]. (2006). Tratado de Libre Comercio República Dominicana, Centroamérica, Estados Unidos. Disponible

https://www.wipo.int/edocs/lexdocs/treaties/es/caftado/trt_cafta_do.pdf.

Organización Mundial de la Propiedad Intelectual [OMPI]. (1999). Ley de Derecho de Autor y de los Derechos Conexos. Honduras. Disponible en: https://www.wipo.int/edocs/lexdocs/laws/es/hn/hn015es.pdf.

Ortiz, H.R. (2011). La observancia de los derechos de propiedad intelectual jurisprudencia. Organización Mundial de la Propiedad Intelectual (OMPI). Ginebra. Suiza.

Parra Satizábal, C.A. (2002). Relación entre propiedad intelectual y derecho de la competencia: mucho más que asuntos de competencia desleal. La Propiedad Inmaterial, Vol 0, Iss 5, 17, p. 17-36.

Poder Judicial de Honduras. (2000). Ley de Propiedad Industrial. La Gaceta. Tegucigalpa, Honduras. Disponible en: http://www.poderjudicial.gob.hn/CEDIJ/Documents/Ley\%20de\%20Pr opiedad\%20Industrial.pdf.

Poder Judicial de Honduras. (1982). Constitución Política de 1982. Disponible en: http://www.poderjudicial.gob.hn/CEDIJ/Leyes/Documents/Constituci \%C3\%B3n\%20de\%201a\%20Rep\%C3\%BAblica\%20de\%20Honduras $\% 20 \% 28$ Actualizada\%202014\%29.pdf.

Sanromán, R. (2014). La importancia del derecho de propiedad en el desarrollo económico. Universidad Autónoma del Estado de México. Centro Universitario UAEM Valle de México. San Javier Atizapán de Zaragoza, México.

Sistema de Información sobre Comercio Exterior [SICE]. (2019). Ley de Derecho de Autor y de los Derechos Conexos. Derechos de Propiedad Intelectual. Legislación Nacional - Honduras. Disponible en: http://www.sice.oas.org/int_prop/nat_leg/Honduras/lautor.asp.

World Trade Organization [WTO]. (s.f.). Acuerdo sobre los aspectos de los Derechos de Propiedad Intelectual relacionados con el comercio. Disponible en: https://www.wto.org/spanish/docs_s/legal_s/27trips.pdf. 